\title{
An Investigation of Verticality in Tertiary Students' Academic Writing Texts: A Systemic Functional Perspective
}

\author{
Vasemaca T. Ledua Alifereti \\ Tsinghua University, Beijing, China \\ E-mail: alifereti.vasemaca@usp.ac.fj
}

Received: 04-02-2013

Accepted: 26-03-2013

Published: 01-05-2013

doi:10.7575/aiac.ijalel.v.2n.3p.163

URL: http://dx.doi.org/10.7575/aiac.ijalel.v.2n.3p.163

\begin{abstract}
This study, identifies, discusses and recommends specific linguistic features that can be explored by Non-Native English (NNE) students studying at the University of the South Pacific (USP) in Fiji to improve their academic writing texts. Firstly, the status of academic writing in relation to NNE speakers both globally and in Fiji is discussed. Secondly, two concepts 'abstract and metaphorical' mentioned to be lacking in USP student texts are described followed by an explanation of how the two concepts are acquired if viewed from three different perspectives. Thirdly, previous studies conducted that had explored the importance of building verticality in writing are presented. Although a number of studies have explored verticality, there are no records to show how it is represented in circumstantial elements. Next the Transitivity system which is the theoretical framework adopted by the study is discussed with a particular emphasis on Relational processes. It is claimed that abstract and metaphorical relations are made in Relational processes. Moreover, certain linguistic features closely associated with verticality are identified to elicit data. Additionally results are presented and discussed according to research questions asked. Findings prove that indeed circumstances are mostly incongruently realized in Relational clauses. In order to build verticality in tertiary students' academic writing texts, one has to be able to understand abstract and metaphorical concepts and how they are linguistically realized in writing texts.
\end{abstract}

Keywords: horizontal and vertical knowledge structures, abstract and metaphorical concepts, grammatical metaphor, nominalization, rankshifted clauses

\section{Introduction}

Most students who write good English essays in high schools enter tertiary institutions with the belief that they are well equipped with academic writing skills expected of them. This is found to be especially true for Fiji students who are enrolled at the University of the South Pacific (USP) (Deverell, 1989; Khan \& Mugler, 2001). However, once they are given academic writing tasks, they come to realize that while high school writing is opinion-based, writing in tertiary institution is more evidence-based (Alexander, Argent, \& Spencer, 2008). This misconception and language discontinuity between high school and tertiary institution is found to be a major contributing factor to poor academic performance which most often leads to academic failure. This claim is supported by various studies undertaken both globally and in Fiji. For instance in European Higher Education (HE), findings reveal that one third of students fail to complete their dissertation writing due to lack of academic writing skills (Bjork, Brauer, Reinecker, \& Jorgensen, 2003). In a study in the USA, Boice (1993) explains that about $50 \%$ of all students who qualify to write dissertations do not complete because they are not able to express themselves using academic writing conventions. In Australia research findings by Jones (2005) highlight that standards of students' generic skills and attributes in academic writing are declining. Additionally, Bjork (2003) says that poor quality of academic writing mentioned by other colleagues is not an unknown phenomenon, citing an article in a German newspaper 'Die Welt'. In the article titled "The organization of thinking by writing" the author explains that according to assessment by experts, half of the university dropout rate in Germany is due to poor academic writing skills. Similar problems are faced by international students studying in Tokyo University in Japan as presented by Buker (2003) and likewise by Chinese students studying in Canada as reported by Yang (2006).

\subsection{Academic writing problems predominant in Non-Native English (NNE) student texts}

To put into perspective what particular language problems are common in NNE speakers' academic writing, a study undertaken by Tony Silva (1997) is discussed. He collected 72 reports of empirical research that examined undergraduate college NNE student texts against their NE counterparts who were in their late teens and early twenties. About 27 different L1s were represented with native speakers of Arabic, Chinese, Japanese and Spanish as predominant. The subjects were described by Silva as having a high level of English proficiency and exhibited a wide ranging level of writing ability. The writing tasks were mainly short expository or argumentative essays timed for thirty or sixty minute sessions in class or during examinations. Some linguistic elements identified to be lacking are summarized. Those that commented on comparison of the length of writing showed conflicting results. Some mentioned that NNE texts were shorter in word count while other authors argued they were longer. The conflicting findings can be attributed to cultural influence or maybe differences in the cognitive demand of the task. Other errors identified include 
morphosyntactic, lexicosemantic, spelling, punctuation, errors in cohesive device use and preposition errors. In clause structure findings indicate that NNE texts exhibited more coordination and less subordination. Also NNE texts were found to contain less passive voice. Silva mentioned that although there was evidence in NNE text of metaphorical awareness this knowledge was not fully explored to fill in the gaps in the second language vocabulary.

\subsection{Academic writing problems for NNE speakers at the University of the South Pacific (USP)}

The problem of academic writing for NNE students at USP has been an ongoing concern since and even before the introduction of English for Academic Purpose (EAP) in 1993. Although there have not been any other studies recorded in the last ten years or so on the status of academic writing, the few earlier ones conducted all seem to have raised similar findings. Problems identified include: grammatical errors, unsatisfactory referencing, lack of research, lack of cohesion, problems in structuring of text, vagueness in expression, problem in constructing an argument, inability to use the appropriate style and lack of vocabulary (Khan, \& Mugler, 2001). The academic writing problems highlighted are similar to those encountered by NNE students in other parts of the world. In particular, two concepts mentioned to be lacking which this study explores are on the use of 'abstract and metaphorical concepts'. This language gap therefore becomes a hindrance to acquiring the necessary academic writing skills at tertiary institutions. To address the identified gap the current study forecasts a text that incorporates both abstract and metaphorical concepts. A text that embodies the two concepts thus is representative of a hierarchical or vertical knowledge structure. This is the knowledge structure required in order for one to effectively participate in one's chosen academic discourse community.

\subsection{What is a vertical knowledge structure?}

Verticality, a type of knowledge structure is advocated to address the academic writing problem identified to be prevalent with NNE students at USP. This idea was first introduced by the British anthropologist and linguist Basil Bernstein (1971) when he was researching on why students who come from low socio-economic backgrounds were not doing as well as those students from the upper middle class. A factor identified that disadvantaged the lower socioeconomic students is the language disparity between the home and school. Findings revealed that students from the upper middle class did fairly well in school because the language they use at their various homes is the same language used in school. This example can be related to the Fiji context where students use a different language in their respective homes while the language of instruction in school is English.

After discovering the negative effects of this language mismatch between the home and school, Bernstein (1971) furthered his study into the way knowledge is structured in relation to what is taught. He thus came up with 'classification and framing theory'. Classification relates to content chosen and framing refers to examination where what is taught becomes legitimized. Bernstein's intension was to highlight that if the dominant group in society continues to dictate what content to include, the disadvantaged group will continue to be marginalized. A significant outcome of this research was the development of the two knowledge structures - horizontal and vertical (see Figure 1). Bernstein found out that students with horizontal knowledge structures are those that can only comprehend things that are immediate and concrete. When it comes to abstract, mediated and metaphorical they have not yet acquired the skills to accomplish such thinking capabilities. This is how they are disqualified when competing with the advantaged group. They fail not because they are mentally deficient but because they have yet to develop and acquire the skills in exploring abstract and metaphorical concepts. This study explores two other alternative views found to be conceptually congruent with Bernstein's horizontal and vertical knowledge structure. Vygotsky (1987), although a psychologist also raises similar views with Bernstein concurring that higher cognitive function which is similar to verticality is socially originated.

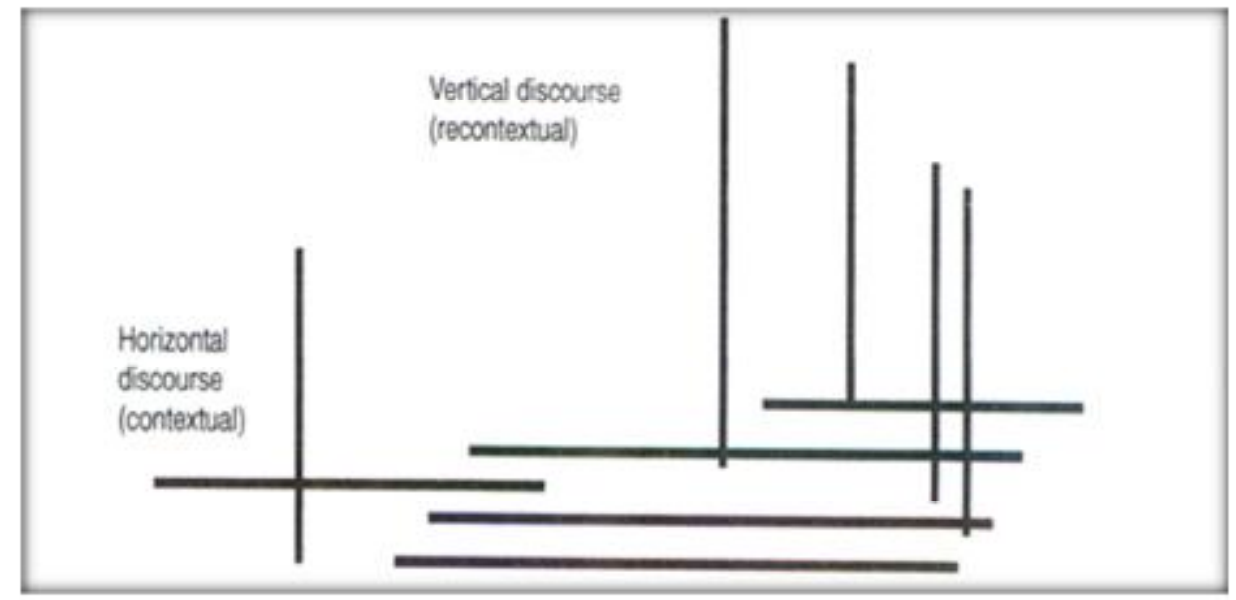

Figure 1. Horizontal \& vertical knowledge structures (O’ Halloran, 2007: 209)

Vygotsky classifies human cognition into two parts: lower and higher cognitive functions. He argues that a child is born with lower mental functions which include the five senses, reactive attention, spontaneous memory and sensorimotor intelligence. Both horizontal knowledge structure and lower cognitive functions are not internally controlled but they are triggered by external stimuli. The lower mental functions develop as a child matures but they do not grow to become higher cognitive functions. One wonders how many students leave the school system but have not grown out of these lower cognitive functions. On the other hand higher cognitive functions are qualitatively different from lower mental 
functions in the way they are acquired and developed. Language as a cultural artefact or psychological tool transforms the lower mental processes into a new type of psychological functioning that are acquired as a result of teaching and learning. Attaining this stage means, a student is able to comprehend and use language both abstractly and metaphorically.

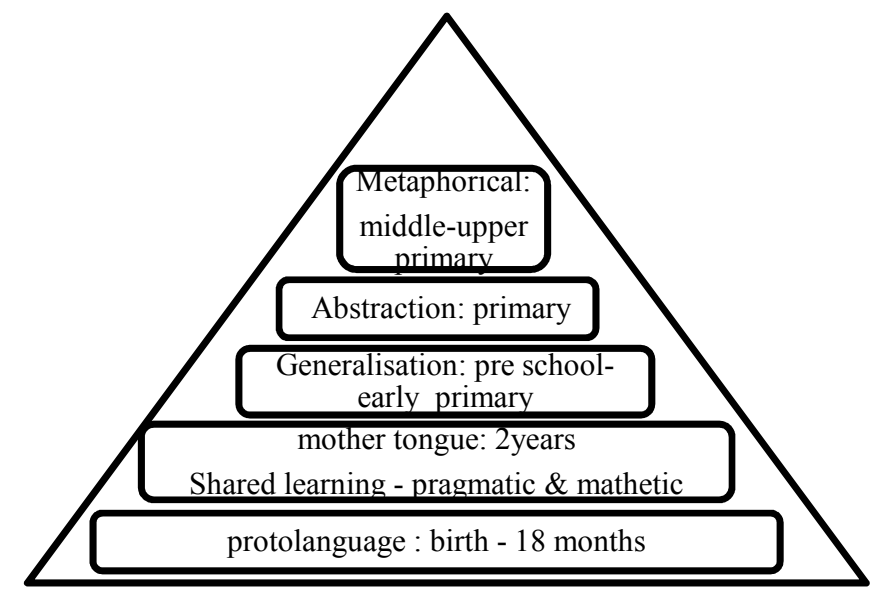

Figure 2. Halliday's Language Development stages in L1

Another similar view is between 'commonsense and educational' knowledge. Halliday defines commonsense as:

fluid and indeterminate, without clear boundaries or precise definitions: it does not matter exactly where a process begins or ends, or what is one phenomenon and what is the other. It foregrounds processes - actions and events. Educational knowledge is defined as determinate and systematic: the categories are organized into conceptual structures with defined properties and explicit interrelations; foregrounds things, persons and concrete objects, then later on increasingly abstract and virtual objects that are needed to explain how things behave (Halliday, 1994a:379).

Like horizontal and lower cognitive functions, commonsense knowledge involves unconscious learning. In the school context, learning demands a shift from unconscious to conscious. This means shifting from lower and horizontal to vertical and higher cognitive functions. From the three perspectives the most important mediating tool in the shift from conscious to unconscious is language as reflected in Figure 3. To further elaborate on abstract and metaphorical concepts it is fitting to also mention Halliday's (1994a) 'Language Development theory' (see Figure 2). In learning one's First Language (L1) or Mother Tongue he identifies several stages of which abstract and metaphorical are situated at the top of the hierarchy. It is estimated by the time a child enters primary school he/she has already acquired the use of generalization. The other two stages abstract and metaphorical are supposed to be developed in the school context. However for most of the schools in Fiji, with the English only rule adopted and vernaculars banned the child's chances of reaching this stage in their Mother Tongue are often compromised. With a new language used for instruction in schools most students and teachers do struggle with this process. Those who fail to negotiate the shift between unconscious to the conscious are sure to become failures in the educational context. Thus, an awareness of the triad perspective is suggested to assist students make a smooth transition which is anticipated to facilitate acquiring of a vertical knowledge structure.

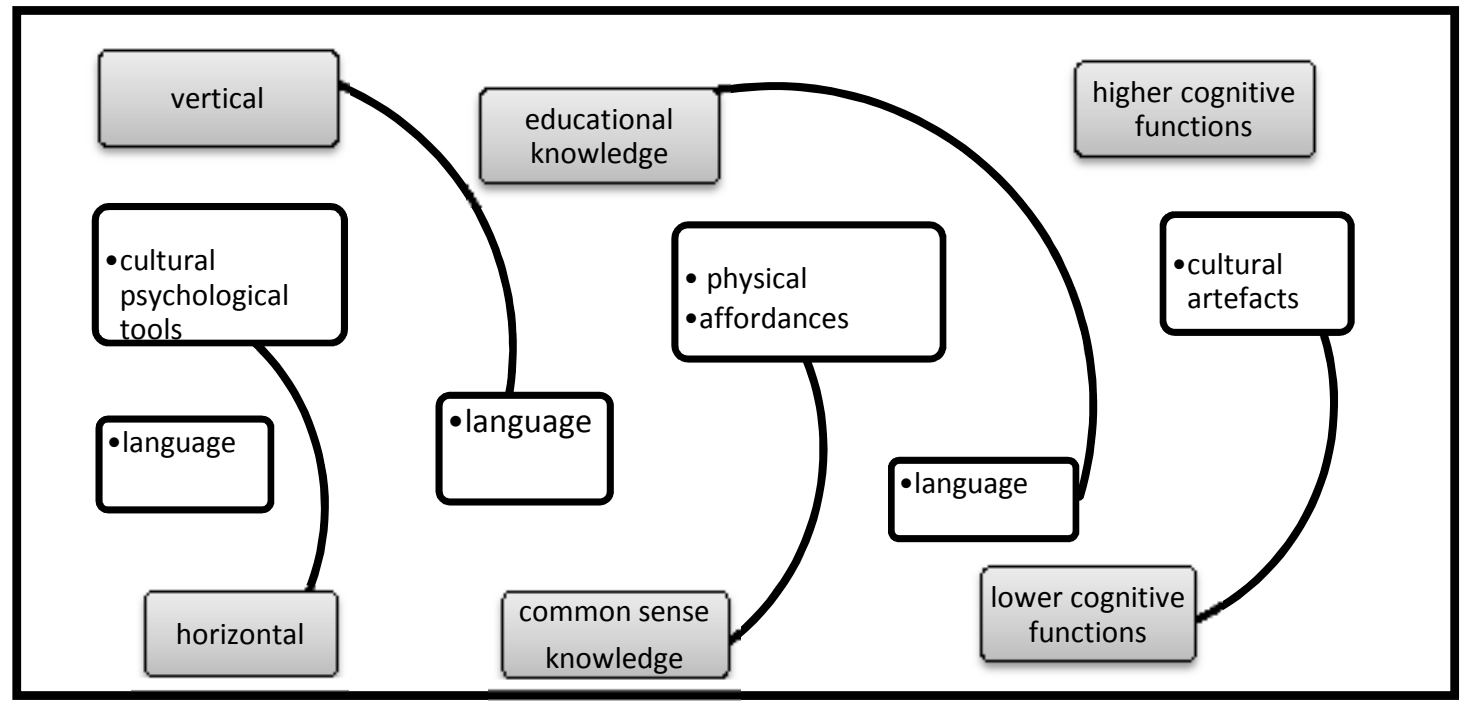

Figure 3. A triad complementary view of verticality 


\section{Literature Review}

Although a number of studies are recorded to have been conducted in relation to the importance of verticality in improving writing quality, none has specifically looked at the use of circumstances. A study to find how students explore linguistic features of verticality was carried out in England by Christie and Macken-Horarick (2007). To gather data they looked at a text written by a school student, who is a NE speaker from England. The text analyzed was of Cultural Studies and graded above level 7, the highest level used and it was given the highest mark available. Some linguistic features associated with verticality identified were sparingly used in the text include; dense nominal groups and rankshifted clauses. A similar study was carried out by Martin agreeing that the most important resource in developing verticality is nominalization and grammatical metaphor (2007:38). To highlight this concept he used Science exemplars arguing that Science taxonomies are relatively comprehensive, deep and precise. For instance they classify and sub-classify from the very general at the bottom of the pyramid to the most specific at the top of the apex. In this process placement of entities in a hierarchy and the use of specialized and technical words are also common. Additionally, the sequence of activities is more on circumstance of 'cause' (Martin, 2007: 41). However, in regards to studies conducted on 'circumstantial elements' none is recorded but Thompson (1996) iterates researchers choose not to explore 'circumstances' because of its fluidity. There are no slots where they can be specifically identified; they are always shifting from initial, middle or final positions. SFG nevertheless has developed a patterned way that is explored in this study where circumstances can be analyzed.

\subsection{Systemic Functional Grammar (SFG) and the Transitivity system: Theoretical Framework}

From the point of view of traditional grammar when Transitivity is discussed, it specifically involves the verb. However in SFG, Transitivity does not only involve the verb or 'process' but includes all the principle elements in the clause the process itself, participant and circumstance. This is because the choice of process type is not independent but impacts the other two principle elements in the clause - participant and circumstance. The Transitivity system represents the world into a manageable set of process types with respective participant roles (Halliday, 1994b:106). It is the system in which the clause is realized as 'representation'. One's experiences are replayed and modeled in the form of text. It is this system that people refer to when talking about meaning as 'content'. Although SFG provides six process types, this paper will only focus on the three major processes: Material, Mental and Relational.

\subsubsection{Material processes}

Material processes are those that involve the outer experiences of actions and events. Things happen and people or other actors do things or make things happen. In Material processes most of the doing or happenings are concrete and immediate. Some examples with relevant participant roles are shown in Table 1.

Table 1. Material processes

\begin{tabular}{llll}
\hline 1. & Jerry & caught & the ball \\
actor & process & goal \\
2. Jerry & ran & through the door \\
actor & process & adjunct \\
\hline
\end{tabular}

\subsubsection{Mental processes}

Mental processes on the other hand reflect inner experiences of consciousness. This involves a sort of replay of the outer. It is quite distinct from Material processes in a number of significant ways. For example it only involves one human participant, the one that is doing the sensing identified as the 'senser' in the clause. Secondly the 'phenomenon' that is being sensed cannot do anything or have anything done to it. This is because it is perceived as 'fact'. Thirdly the 'tense' that is closely associated with Mental process is often of the simple present type because it is not bound to any time relative to the time of speaking.

Table 2. Mental processes

\begin{tabular}{llll}
\hline & senser & Mental process & phenomenon \\
\hline 1. & I & dislike & your manner \\
2. I & do not know & the answer \\
& phenomenon & Mental process & senser \\
1. Your manner & displeases & me \\
2. It (the answer) & escapes & me \\
\hline
\end{tabular}

A fourth feature typical of Mental process is its bi-directionality. This is where either the 'senser or phenomenon' can be placed in the subject slot. Some examples are illustrated in Table 2. 


\subsubsection{Relational processes}

If 'Material' is the 'process of doing' and 'Mental' is the process of sensing, 'Relational' is the process of 'being'. This means that in Relational clauses there are two parts to the being: something is said to be something else. In other words a relationship is set up in the clause between two entities. It is in the Relational clause that one can make generalizations; to relate one fragment of experience to another, such as; 'this is the same as that, or this is a kind of the other' (Halliday, 1994b: 107). It is here that grammar recognizes two other processes: those of 'classifying and identifying'. Processes of classifying are labeled as Attributives and those of identifying are called Identifying. These two process types can operate and further bring out three other semantic relations: (i) intensive - ' $\mathrm{x}$ ' is ' $\mathrm{a}$ ', (ii) circumstantial - ' $x$ ' is at ' $a$ ' where 'is at' stands for 'is at, in, on, for, with, about, along, etc., (iii) possessive - ' $x$ has a'. Some examples are shown in the Table 3. In the Attribute mode an entity has some quality ascribed to it. Structurally this quality is labeled Attribute and the entity to which it is ascribed is called the Carrier.

Table 3. Relational clauses (Halliday, 1994b:119).

\begin{tabular}{|c|c|c|c|}
\hline & mode/type & Attributive & Identifying \\
\hline \multirow[t]{2}{*}{1.} & intensive & Sarah is wise & Tom is the leader. \\
\hline & & & The leader is Tom. \\
\hline \multirow[t]{2}{*}{2.} & circumstantial & The fair is on Tuesday & Tomorrow is the tenth \\
\hline & & & The tenth is tomorrow \\
\hline 3. & possessive & Peter has a piano & The piano is Peter's. \\
\hline
\end{tabular}

There are four characteristics of Attributive clauses which distinguish them from Identifying ones.

1. The nominal group functioning as Attribute is indefinite and can be an adjective or a common noun as Head. It cannot be a proper noun or pronoun.

2. The verb realizing the process is one of the ascriptive classes:

- Phase: inceptive - become, turn (into) grow (into) get, go.

- Phase: durative - remain, stay (as) turn out, end up (as)

- Phase: appearance - seem, appear, qualify, as, turn out, end up (as).

- Phase: sense-perception - look, sound, smell, feel, taste (like)

- $\quad$ Neutral - be, feel

3. The probe for such clauses is 'what?, how? or What...like? E.g What is Paula?

4. These clauses are not reversible hence there are no passive forms. (Halliday, 1994b: 120-121)

Table 4. Attributives

\begin{tabular}{lll}
\hline 1 & Paula & is a poet \\
& carrier & attribute \\
2 & The fair & lasts all day \\
& carrier & attribute \\
\hline
\end{tabular}

In the Identifying process, something has an identity assigned to it. This means that one entity is being used to identify another. For example; ' $x$ ' is identified by ' $a$ ', or ' $a$ ' serves to define the identity of ' $x$ '. Structurally we label the ' $x$ ' element to be identified as the Identified and the 'a' element, which serves as the identity as the Identifier.

Some characteristics of Identifying clauses are listed below:

1. The nominal group functioning as Identifier is definite. It has a common noun as head, with 'the' or other specific determiner or else a proper noun or pronoun. The only form with adjective as head is the superlative. For example Jane is the fastest runner.

2. The verb realizing the process is one from the 'equative' classes :

- role - play, act as, function as, serve as

- $\quad$ sign - mean, indicate, suggest, imply, show, betoken, mark, reflect

- equation - equal, add up to, make

- $\quad$ kind/part - comprise, feature, include

- $\quad$ significance - represent, constitute, form

- example - exemplify, illustrate

- $\quad$ symbol - express, signify, realize, spell, stand for, mean 
- $\quad$ neutral - be, become, remain (Halliday,1994b:123).

3. The probe for such clauses is 'which? who? which/who...as? (or what? For example; Who is the one in the back row? Which are the deadliest spiders? These clauses are reversible. Although Attributive and Identifying clauses can further be categorized as intensive, possessive and circumstantial, the most commonly explored in academic writing is circumstantial (Halliday, 1994b).

\subsubsection{Thesis Statement}

Abstract and metaphorical concepts can be incorporated into student texts by exploring incongruent circumstances in Relational clauses. To support this claim answers to the following questions are sought

Question.1 How are incongruent circumstances distributed in Relational clauses?

Question.2 What linguistic features representative of abstract and metaphorical concepts are prevalent in circumstantial elements used in student texts?

Question.3 In regards to verticality what can be interpreted from the comparison between the two cohorts - NE and NNE texts?

\section{Method}

To obtain data an exploratory interpretive approach is adopted. This choice is determined while taking into account a number of factors that are compatible and aligned with this research design. Because data selection is made using convenience sampling, it is anticipated to be ungeneralizable but justifiable (Nunan, 1994).

\subsection{Subjects of study}

Two sets of data are used in this study. The first set comprising of 30 argumentative writing scripts are from NE speakers who are final year tertiary students of Michigan University in the USA. The second set also comprising of 30 scripts are from NNE students from USP in Fiji.

\subsubsection{NE Speakers}

Due to the difficulty encountered in acquiring NE data, the current study adopted 'convenience sampling technique' in data selection (Wen, 2001: 138). This suggests the researcher used data that are readily available. For this particular group data used as referenced corpora were extracted from the Michigan University Elicorpora website (MICUSP, 2010). NE students identified to participate are those from the School of Humanities and whose writings are graded as A+. Additionally, scripts selected are from students within the age range 20 to 22 years.

\subsubsection{NNE Speakers}

Data selected for NNE texts are from second and final year students due to difficulties encountered in acquiring all final year student texts. This cohort of 30 included students from Fiji with ages ranging from 20 to 22 years. Scripts obtained are those in the ' $A$ ' and ' $\mathrm{B}$ ' grades because it was not easy to acquire A grade papers. It is imperative to understand that although these students are commonly labeled as English as a Second language (ESL) students majority of them may not use English as a second but a third or fourth language depending on which island of the Fiji group they are from. Hence for the purpose of this study NNE will be used instead of English as a Second Language (ESL)

\subsection{Text type chosen to be analyzed}

An argumentative text type is chosen because it explores persuasive rhetorical strategies which require exploration of higher cognitive skills. An argument suggests there is tension between the author and the audience/reader. Therefore, it is the responsibility of the author to persuade the audience/reader to agree with the stance adopted.

\subsection{Data analysis method}

Firstly, analysis looks at the various types of circumstances. Secondly expansion types are discussed to show how they influence the creation of the circumstantial semantic space. Thirdly incongruent circumstances are analyzed both at the word and clause level to determine if the following concepts are incorporated: nominalization, grammatical metaphor and rankshifted clauses.

\subsubsection{Types of circumstances}

In traditional grammar 'circumstance' is normally looked at as an optional element in the clause. Circumstance as generally understood provides background information mainly addressing the WH- questions of 'what...where...when...why... and how'. In this case modal adjuncts, conjunctive adjuncts and circumstantial adjuncts are congruently realized by prepositional or adverbial phrases. From the perspective of SFG they are recognized in the grammar of Mood but not in the Transitivity system. This paper attempts to explore how circumstances are realized in Relational clauses. This standpoint is adopted to verify Halliday's (1994b) theory that in Relational clauses circumstances are incongruently realized. This type of tension when created within or between clauses engenders grammatical metaphor. Grammatical metaphor is mentioned by many linguists and educationists as the stepping stone to attaining verticality (Christie, \& Macken-Horarick, 2007; Martin, 2007; Maton, 2007).

Figure 5 illustrates some circumstances identified by Halliday viewed in a hierarchy. 


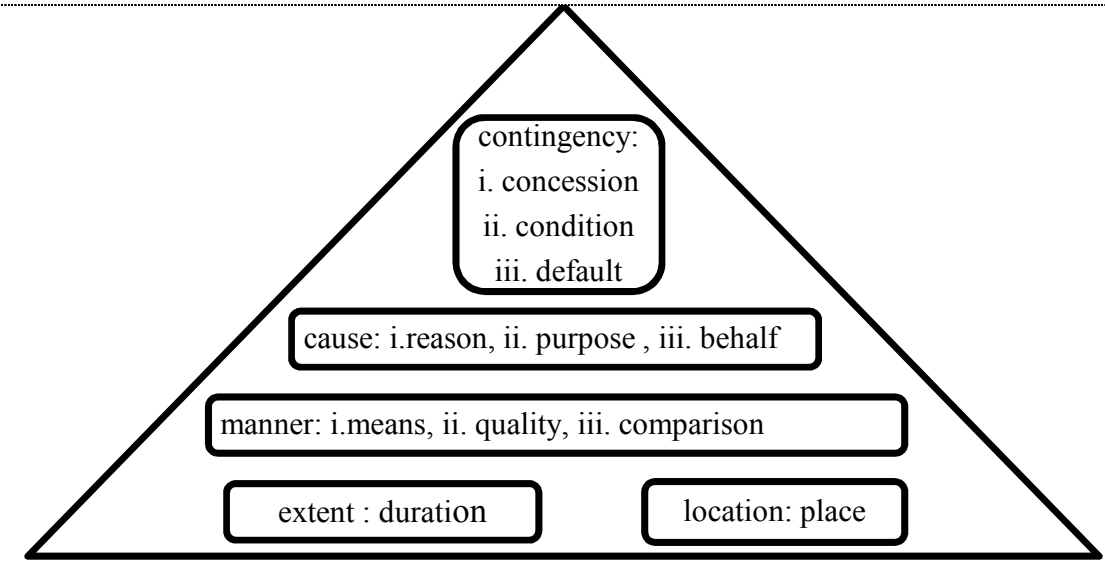

Figure 5. Circumstantial hierarchy

\subsubsection{Logico-semantic relations: expansion strategies}

Expansion is the second feature identified to induce data. The assumption is that an analysis of the kinds of logicosemantic links used in the circumstance contributes significantly to the complexity of a text. Systemic Functional Grammar provides two systemic dimensions (Halliday, 1994b:216). The first is the system of interdependency or tactic system comprising of parataxis and hypotaxis which is general to all complexes - word, group, phrase and clause alike. The second is logico-semantic system of expansion and projection which is specifically an inter-clausal relation - or rather a relation between processes. In regards to interdependency or the tactic system Halliday defines parataxis as the linking of elements of equal status. This is similar to coordination in traditional grammar. Both the initiating and continuing elements are free in the sense that each could stand as a functioning whole. Hypotaxis on the other hand is similar to subordination in traditional grammar which involves the binding of unequal elements. The dominant element is free but the dependent element is not. Some examples of clause complexes are illustrated in Table 4.

Table 4. Clause complexes

\begin{tabular}{|c|c|c|}
\hline EXPANSION & paratactic & hypotactic \\
\hline $\begin{array}{l}\text { elaboration } \\
\text { extension }\end{array}$ & $\begin{array}{l}\text { John didn't wait, he ran away. } \\
\text { John ran away and Fred stayed } \\
\text { behind }\end{array}$ & $\begin{array}{l}\text { John ran away which surprised everyone. } \\
\text { John ran away whereas Fred stayed } \\
\text { behind. }\end{array}$ \\
\hline enhancement & John was scared so he ran away. & John ran away because he was scared. \\
\hline
\end{tabular}

Expansion is when a primary clause is expanded by a secondary clause (Halliday, 1994b). From the point of view of Transitivity this also implies how a major process is expanded by a minor process. Hence when talking about expansion it can be understood within three sub-types: (i) elaboration (ii) extension and (iii) enhancement. In the sub-type 'elaboration' there are three other distinctions made namely; exposition, exemplification and clarification. In exposition another clause restates what has been mentioned in a different way.

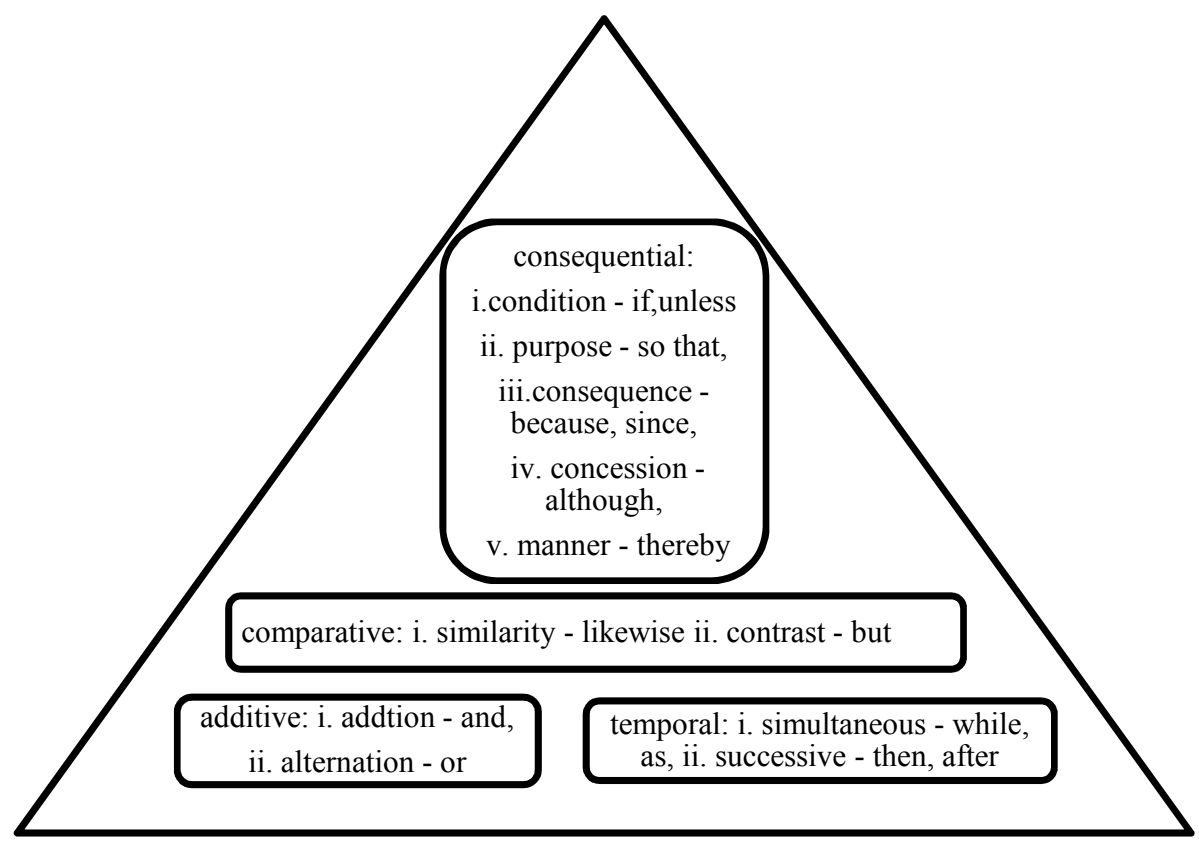

Figure 6. Types of conjunctions 
In regards to exemplification examples are given to further support and illustrate the argument put forth while in clarification there is extra information given to further clarify one's point of view or idea. For 'extension' one clause extends the meaning of another by adding something new to it. What is added maybe just an addition, a replacement or an alternative. In enhancement one clause enhances the meaning of another by qualifying it in a number of possible ways: by reference to time, place, manner, cause or condition. It is apparent that elements encompassed in enhancement strategies (see Figure 6) overlap with those observed for circumstance (see Figure 5). According to discussions on the concept of expansion it is clear that the elements are built hierarchically from elaboration to extension and it is evident that enhancement is at the top of the hierarchy.

\subsubsection{Element that follows Thing: rankshifted clause}

Elements that follow Thing/Head noun are those items which in their own structure are of a rank higher or at least equivalent to that of the nominal group. This study asserts that texts that fully exploit this element is arguably said to be of a higher quality. In writing these elements are called 'rankshifted clauses' and they function as qualifiers. Some examples are given below.

\section{Defining relative clauses}

All rankshifted clauses are 'defining relative' clauses also known as 'restrictive relative' clauses. All full defining relative clauses contain a relative pronoun and this may be a Wh-pronoun such as who, whom, which, whose, where, when or it may be that. Some examples are given with relative clauses italicized.

(i) Any dead circuit/is/one that can be worked on.

(ii) Michie's added insight here /is/one that gives a face to those who are affected and calls on educational reformers to implement reforms that do as he does: see adolescents in urban schools as real people with real potential.

\section{Non-finite relative clauses}

Non-finite relative clauses are often called 'reduced relative'. In the examples given the italicized structures have no subject or finite but they are clauses nevertheless: non-finite clauses. There is an obvious systematic relationship here to clauses with a relative pronoun as subject and a finite 'be'.

(i) Their appeal/ is accepted/provided they abide by the terms of reference.

(ii) This amendment also/defines/ bilingual education as instruction in English and in the native language of the student to allow the student to progress effectively through the educational system.

\subsubsection{What is grammatical metaphor?}

Metaphor as it is generally understood is a figure of speech. If something is said to be metaphorical, it must be metaphorical by reference to something else. It is used for something resembling that which it usually refers to. Halliday discusses two ways of arriving at metaphorical meaning. When seen from below, the focus is on lexis as metaphor. It is the variation in meaning of a given expression that is sought. When seen from above the focus is on the whole clause and it is the variation in the expression of a given meaning that has to be determined. In this way literal is seen not to be appropriate hence the less metaphorical variant is referred to as 'congruent. The two perspectives are shown in Figure 7.

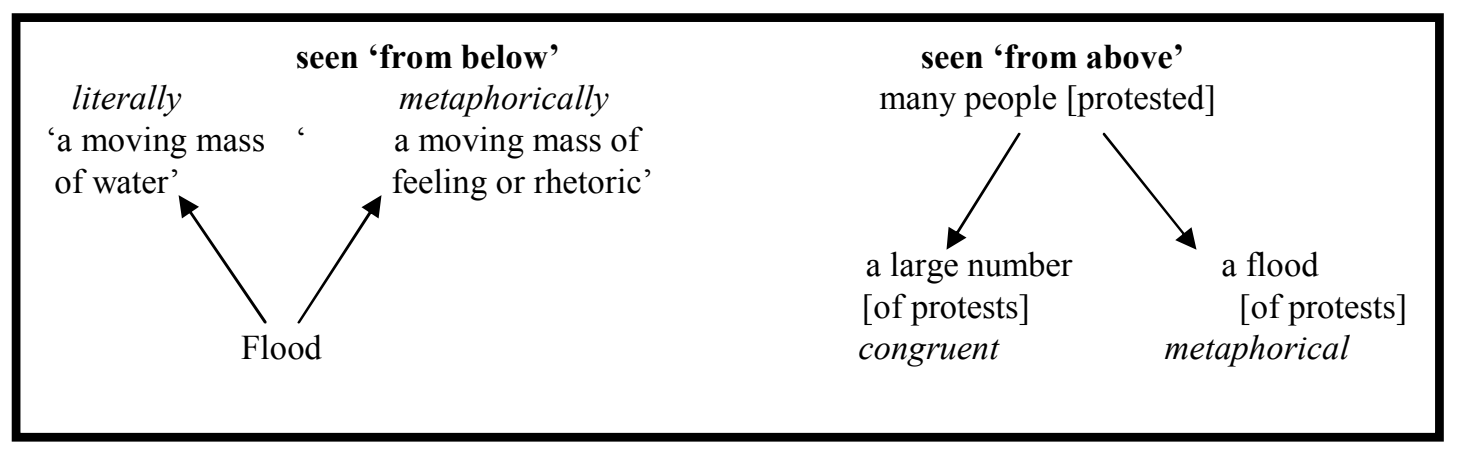

\subsubsection{Nominalization}

Figure 7. Metaphorical meaning

Nominalization is another linguistic concept which normally is a stepping stone to grammatical metaphor. It is when the process by which events, qualities and relationships come to be represented not as verbs, adverbs or conjunctions but as things and nouns. For instance the process 'moves' if nominalized it is constructed as a noun 'motion'. In the case of a property such as 'it is hard' it changes to a noun as 'hardness'. Nominalized entities appear in academic language for a number of reasons: to create technical terms, to create cause-and-effect relationships between disparate phenomena, to synthesize and systematize detailed information and to create measurable entities (Martin, 2007). 


\section{Results and Discussion}

Research findings are illustrated and discussed according to the research questions asked.

\subsection{How are incongruent circumstances distributed in Relational clauses?}

Analysis proves that circumstances in Relational clauses are mostly incongruently realized.

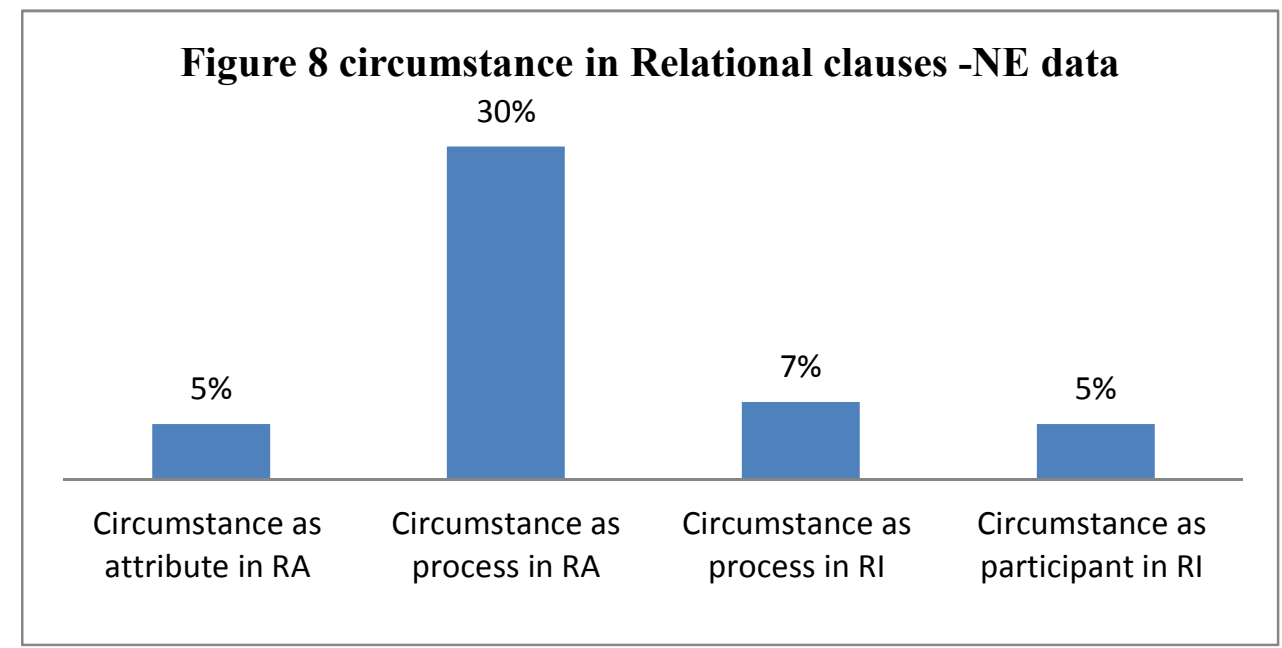

This is illustrated in Figure 8 for NE data and Figure 9 for NNE data where it is evident that exploitation of attributes or congruent circumstances is minimal for both cohorts. Figure 8 shows that of the $47 \%$ of circumstances explored in Relational clauses by NE texts, only $5 \%$ are congruent and the remaining $42 \%$ are incongruent. In the case of NNE data out of the $34 \%$ of circumstances manipulated only $8 \%$ are congruent. The illustration supports the claim that there are more incongruent as opposed to congruent circumstances in Relational clauses.

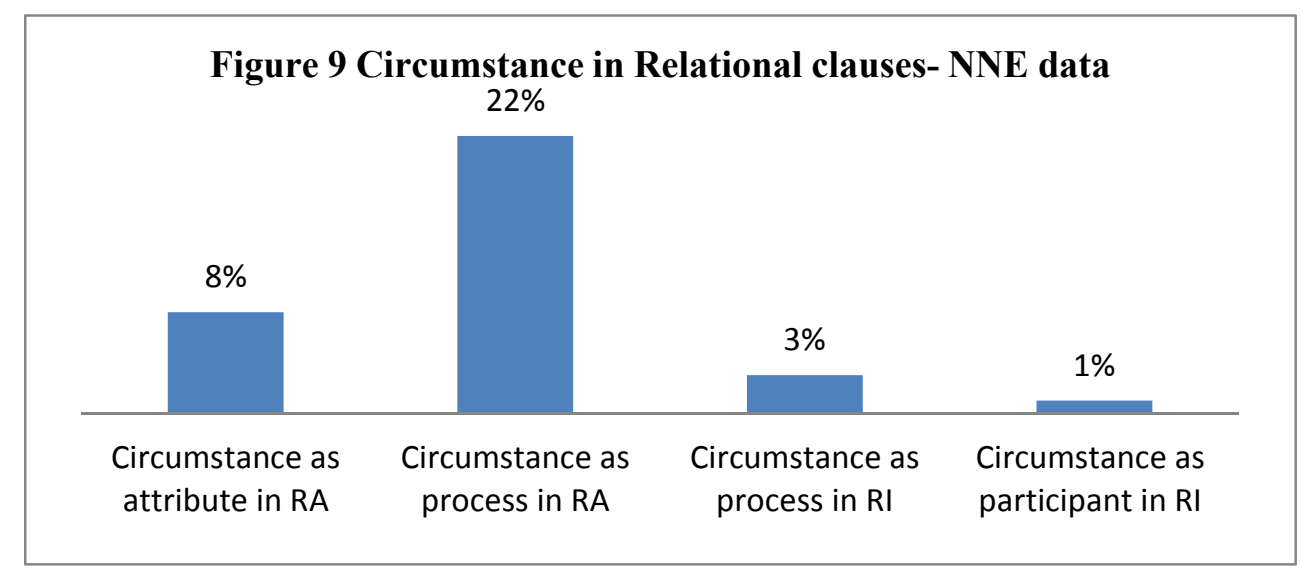

4.2 What linguistic features representative of abstract and metaphorical concepts are prevalent in student texts?

This question looks in-depth at the three incongruent circumstantial realizations in Relational clauses -

(i) circumstance as process in RA, (ii) circumstance as process in RI, and (iii) circumstance as participant in RI.

Each incongruent circumstance is analyzed at two levels -

(a) 'word' which includes both the nominal and verbal group. This analysis seeks to determine what is used as a substitute instead of the grammatical labels.

(b) 'clause' to ascertain the clause types manipulated in regards to logico-semantic relations and how choices made influence the circumstantial semantic space created.

4.2.1 Circumstance as process in RA for NE data

Example.1: The impact of the Internet and technology on children today (Carrier) is (process) unavoidable: children are increasingly immersed in the digital world through a variety of media (Attribute).

A. Word level :

(i) Verbal group: instead of the process 'avoid' it is realized by an adjective 'unavoidable'. In this context 'unavoidable' can be understood both as a verb and an adjective.

(ii) Nominal group: '...the digital world...' - The classifier 'digital' is semantically charged and can be unpacked as; (a) a world that is revolutionized or dominated by the use of computers, (b) a world that uses machines run by electronics to process data, or (c) a world that is dominated by the use of numbers... \& etc.

B. Clause level :

(i) Expansion type: elaboration

(ii) Circumstantial type: manner

(iii) What comes after Thing - a prepositional phrase, however it has been accepted that at times prepositions are processes in disguise. For instance in this context the preposition 'through' can be substituted with the process 'using a variety of media'. It is therefore also fitting to claim that a non-finite rankshifted clause comes after Thing. 


\subsubsection{Circumstance as process in RA for NNE data}

Example .2: Likewise, another important factor of reinforcement being emphasized by Skinner (Carrier) is (process) the use of positive reinforcement (Attribute).

A. Word level

(i) Verbal group: the process 'use' is used in this context as a nominal group 'the use' $=$ deictic + noun.

(ii) Nominal group: 'positive reinforcement' = adjective + noun. The Head noun is derived from a process 'reinforce'.

B. Clause level

(i) Expansion type: none.

(ii) Circumstance type: manner.

4.2.3 Circumstance as process in RI for NE data

Example.3: On the surface, the grey zone (Identified) demonstrates (process) the absence of a clearly demarcated line between good and evil (Identifier).

A. Word level

(i) Verbal group: instead of a process an abstract meaning conveyed through the noun 'absence' is inserted.

(ii) Nominal group: an abstract noun - '... a clearly demarcated line between good and evil'. The Head noun 'line' is prequalified by an adverb 'clearly' and a process 'demarcated' and postqualified by a prepositional phrase.

B. Clause level

(i) Expansion type: elaboration.

(ii) Circumstance type: manner - qualities.

(iii) What comes after Thing: prepositional phrase 'between good and evil.'

4.2.4 Circumstance as process in RI for NNE data

Example 4: Narrative (Identified) can be defined (process) as the relation of a connected series of events (Identifier).

A. Word level

(i) Verbal group: the process 'relate' is used in this context as a noun 'relation'.

(ii) Nominal group: 'series of events' is premodified by a process 'connect' used as an adjective.

B. Clause level

(i) Expansion type: elaboration.

(ii) Circumstance type: manner.

(iii) What comes after Thing: none.

4.2.5 Circumstance as participant in RI for NE data

Example 5: The underlying theory of the plan (Identified) is (process) that if the appropriate amount of financial support is received, HIV/AIDS could be so effectively subdued that infection rates would stabilize and begin to taper, eventually even diminishing (Identifier).

A. Word level

(i) Verbal group: a process 'infect' is used in this clause as a nominal group 'infection'.

(ii) Nominal group: the whole clause 'that if the appropriate amount of financial support is received, HIV/AIDS could be so effectively subdued that infection rates would stabilize and begin to taper eventually even diminishing,' conveys an abstract meaning and functioning as a participant in this context.

B. Clause level

(i) Expansion type: enhancement.

(ii) Circumstance type: contingency - condition.

(iii) What comes after Thing: a non - finite clause '...that infection rates would stabilize and begin to taper, eventually even diminishing'.

4.2.6 Circumstance as participant in RI for NNE data

Example 6: This question as the Dube points out (Identified) is (process) the climax of the scene because it is the point of time that will create a particular space for political intervention (Identifier).

A. Word level

(i) Verbal group: instead of a process it is substituted by a nominal group 'the climax...' conveying an abstract meaning.

(ii) Nominal group: it is realized by the whole clause conveying an abstract meaning '...the climax of the scene...intervention.'

B. Clause level

(i) Expansion type: enhancement

(ii) Circumstance type: cause and effect

(iii) What comes after Thing: non-finite rankshifted clause '...that will create a particular space for political intervention'.

4.3 In regards to verticality what is the status of USP student texts when compared with NE data?

Findings obtained are summarized under the sub-headings word and clause level. This is carried out to determine how abstract and metaphorical linguistic features are explored at the two levels and if there is a significant pattern noted. Secondly in order to determine what is the status of NNE student texts at USP with regards to verticality, an overall analysis is undertaken on the choice of expansion types commonly explored and what circumstantial semantic space is created as a consequence. 
4.3.1 Analysis at the word level

Analysis administered at the word level looks at both the verbal and nominal groups. A glaring finding is the tension created because both verbs and nouns are in many instances not construed by their grammatical labels. Although this is found to be prevalent in both cohorts its exploitation is more complex with NE texts rather than NNE. The choice of nominalization for both verb and noun slots is done to provide a less dynamic and a more synoptic vision of the world. A world in which reality is as if held still, rendered fixed, bound and determinate, so that it can be observed, measured and if possible explained (Martin, 2007). This is a strategy promoted in higher and elaborated registers. Additionally this is the stepping stone by which one incorporates abstract and metaphorical linguistic features into writing texts.

4.3.2 Analysis at the clause level

At the clause level analysis of expansion strategies especially on the choices explored is suggestive. Comparison made on the mean distribution as indicated in Figure 10 for NE data and Figure 11 for NNE data clearly shows the disparity that exists between the two independent variables. The graph for NE data shows that there is a good balance in the exploitation of elaboration and extension but the strength and most of the emphasis is put on the manipulation of enhancement expansion strategies. However, in the case of NNE data the graph in Figure 11 illustrates that choice of expansion is mostly centered on elaboration types. It can be concluded that while NE data are fully exploiting this linguistic feature, NNE data are still lagging behind. A comparison of expansion type reveals that NNE data are still positioned at the middle and lower end of the hierarchy. A progression is developed when and as a writer develops maturity. According to Martin the shift towards consequential conjunctions indicates a movement away from the hereand-now of everyday life and towards more abstract and metaphorical discourse.

The main thrust of this study is to highlight that exploitation of circumstantial elements in Relational clauses is a platform where abstract and metaphorical linguistic features can be incorporated into student texts. For the purpose of this study this basically involves making choices on what expansion types to use in order to attain the circumstantial semantic space forecasted. For data NE reference to Figure 10 reflects the choices of expansion types students make to finally come up with the circumstantial semantic space created in Figure 12. It is inherent that clauses are distributed widely taking into account circumstances of manner, cause and contingency. A comparison with the circumstantial hierarchy in Figure 5 depicts that NE students are progressing upward the hierarchy in their exploration of circumstantial types. However, this is not the case with NNE texts.
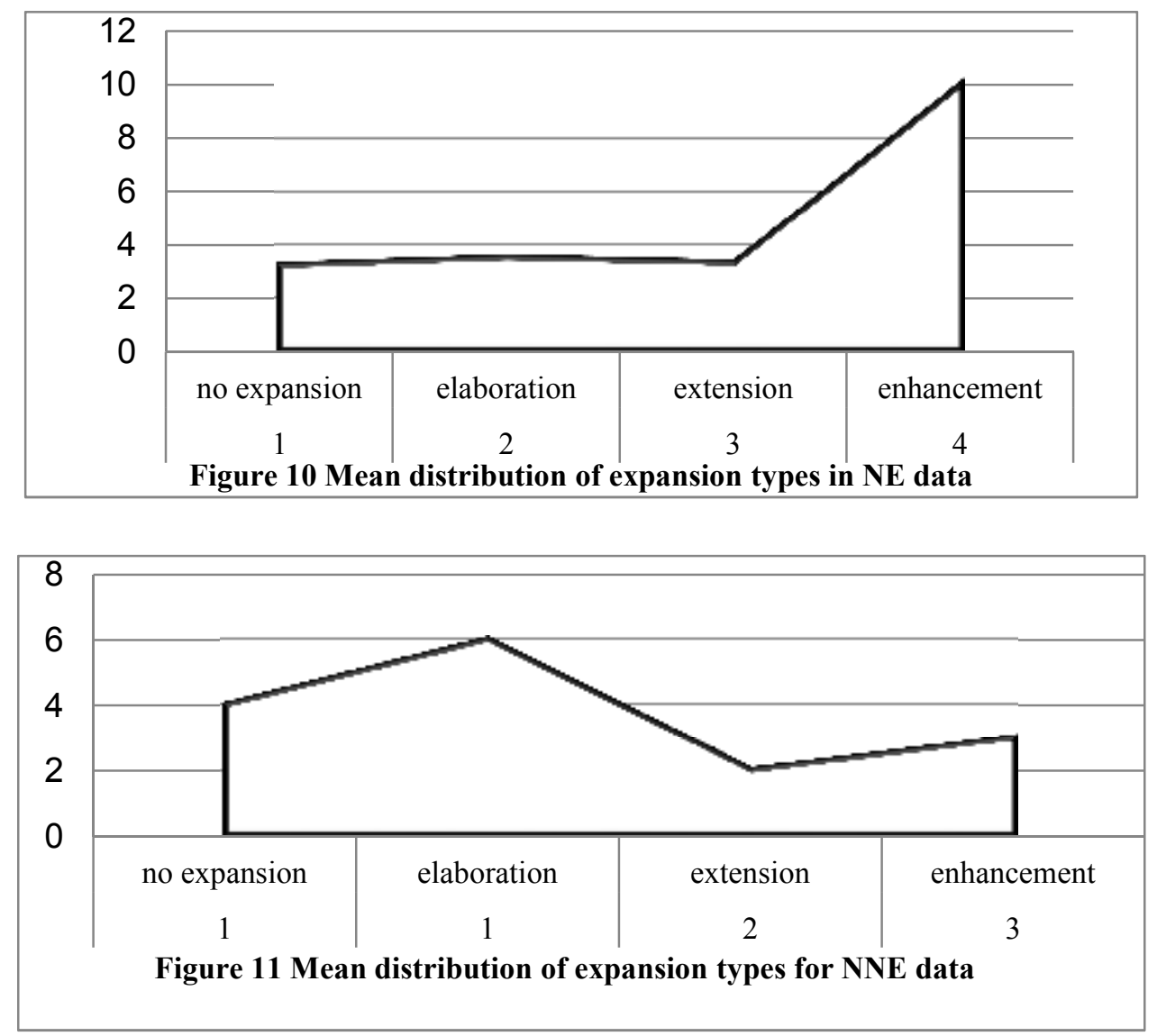

Results gathered show that USP students do not quite fully explore expansion strategies but with the few that do the focus is on elaboration. The choice of this particular expansion strategy results in the creation of the circumstantial semantic space illustrated in Figure 13. The graph symbolizes that placement of NNE students in relation to exploration of circumstantial types is still concentrated more towards circumstance of manner. It is significantly lower for both 'cause and contingency' circumstantial types when compared with NE data. In academic writing and especially at tertiary institutions acquiring skills in the use of 'cause and contingency' rhetorical devices is critical. 


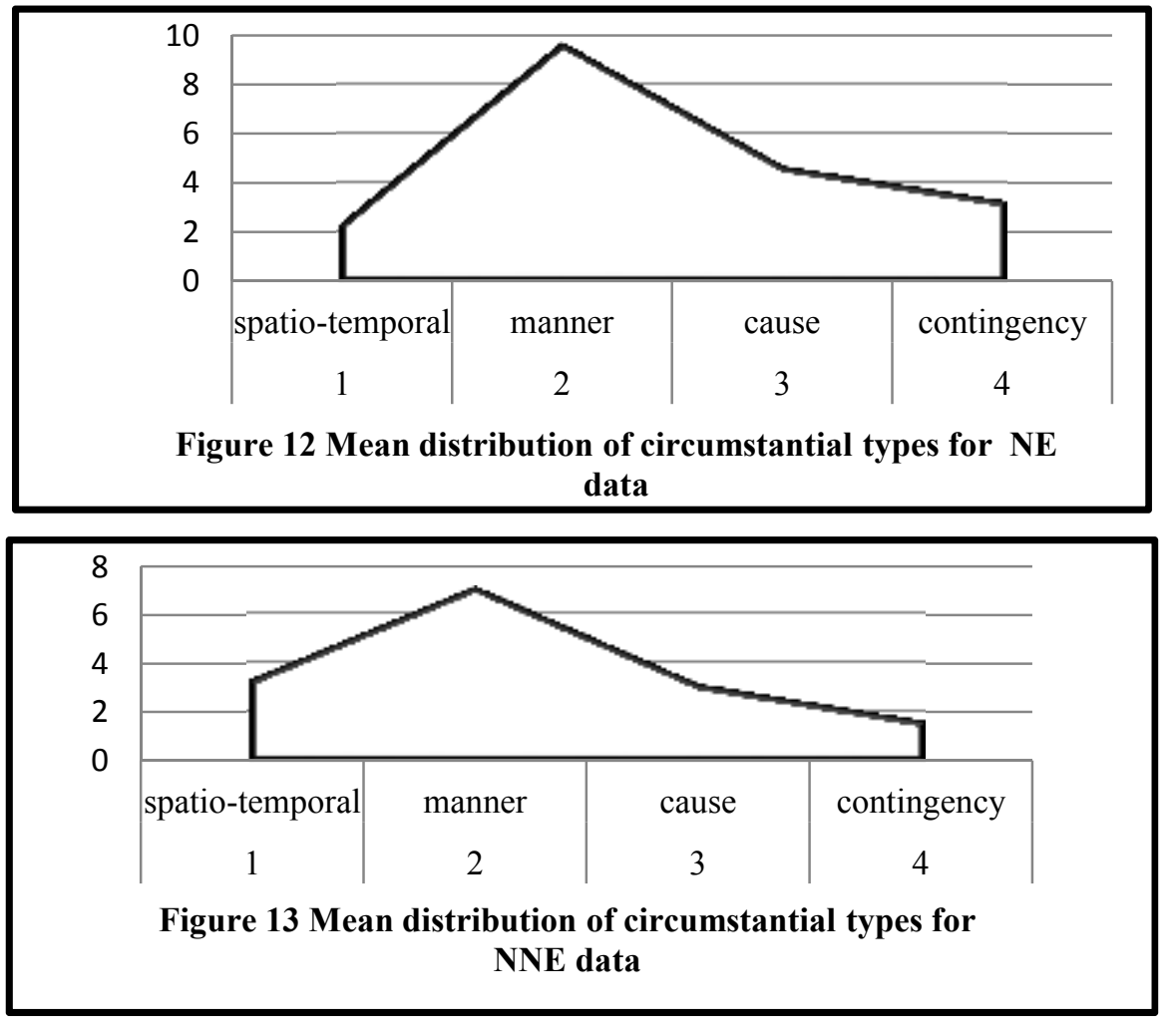

An analysis of the element that comes after 'Thing' particularly focuses on the use of 'rankshifted clauses' as post modification. A significant finding noted is its lack thereof in NNE data while this feature is fully utilized in NE data. Rankshifted clauses as discussed earlier are those items which in their own structure are of a rank higher or at least equivalent to that of the nominal group. It is evident from the analysis that NE data exploit this linguistic feature sparingly. An element that is quite commonly used in NE texts is the exploration of non-finite clauses. These clause types are features used by mature writers as they enhance and build verticality in the clause. The clause functions as a descriptive gloss adding further characterization to something that is taken to be already specific. Moreover the use of non-finite clauses is strategic in the sense that in most instances the participant/subject is left implicit to be presupposed from the primary clause. This is usual for non-finite clauses - the meaning is less specific, both the domain of the dependent clause and its semantic relationship to its domain are left implicit. From the perspective of academic writing in relation to rhetorical strategy this is precisely the reason non-finites are used. On the other hand in the case of NNE data defining relative clauses with finite processes is most common. The difference in the choices made is telling which brings to bear how much there are that have yet to be exploited in order for NNE students at USP to build verticality into their academic writing texts.

\section{Conclusion}

Texts analyzed in this research have proven Halliday's theory that circumstances are indeed mostly incongruently realized in Relational clauses. Out of the three incongruent circumstances it was noted that for both cohorts circumstance as process in RA was the most commonly explored and the least explored was circumstance as participant. This finding proves that in language learning whether it is L1, L2 or language learning explored at another level like in this particular case, 'process' is always the first to be acquired before 'nouns'. Hence it is important for practitioners to understand these stages and to assist students to continue to progress further.

In-depth analysis of these incongruent circumstances at the word and clause level revealed the incorporation of abstract and metaphorical linguistic features some of which were represented in the form of nominalization and grammatical metaphor. In regards to investigation of verticality in USP student texts, expansion type mostly explored was analyzed. Out of the three expansion types - elaboration, extension and enhancement, texts analyzed indicate USP students were mostly using elaboration and extension. Hence interclausal relationships were more sequential as opposed to consequential. Although a number of texts indicated exploration of enhancement expansion types, these were not as salient as in the case of NE texts. The choice of expansion type explored in USP student texts resulted in the creation of a circumstantial semantic space which positioned them towards the middle and lower end of the circumstantial hierarchy as reflected in Figure 13. On the other hand, NE data fully explored enhancement strategies some of which include the use of cause and contingency rhetorical devices. The choice basically positioned NE students towards the upper end of the circumstantial hierarchy when compared to NNE data.

The study has both theoretical and practical implications. In relation to language learning theory, SFG is found to be a holistic approach. Regarding the two concepts mentioned to be lacking in USP students' academic writing texts abstract and metaphorical, the current study has identified and illustrated a theoretical point of departure where they can be explored. This information should assist in policy making at the administrative level and likewise instruction 
formulation at the classroom level. The study involving the use of abstract and metaphorical concepts can be replicated not only at tertiary but at the primary and secondary levels as well. Because this study addresses language problems that affect higher language skills, it can be carried out at the various exit and entry points from primary, secondary and tertiary level to create a clear learning pathway. Additionally this study can be executed in one's Mother Tongue first before moving to the English language. This is a sure way of familiarizing researchers with the concepts first in one's First language. Identification of incongruent circumstantial realizations in Relational clauses will give students an insight on how abstract and metaphorical concepts are incorporated in texts which basically is a stepping stone to building verticality.

\section{References}

Alexander, O., Argent, S., \& Spencer, J. (2008). EAP Essentials. A teacher's guide to principles and practice. Reading RG1 4QS, UK: Garnet Publishing Ltd.

Bernstein, B. (1971). Class, codes and control 1: Theoretical studies towards a sociology of language. London: Routledge \& Keagan Paul.

Björk, L. (2003). Text Types, Textual Consciousness and Academic Writing Ability. In L. Bjork, G. Brauer, L. Reinecker, \& P. Jorgensen (Eds.), Teaching Academic Writing in European Higher Education (pp 29-40). Dordrecht/Boston/London: Kluwer Academic Publishers.

Bjork, L., Brauer, G., Reinecker, L., \& Jorgensen, P. (2003). Teaching Academic English in European Higher Education. Dordrecht/Boston/London: Kluwer Academic Publishers

Boice, R. (1993). Writing blocks and tacit knowledge. Journal of Higher Education, 64, $19-54$.

Büker, S. (2003). Teaching Academic Writing to International Students: Individual Tutoring as a Supplement to Workshops. In L. Bjork, G. Brauer, L. Reinecker, \& P. Jorgensen (Eds.), Teaching Academic English in European Higher Education (pp. 41-57). . Dordrecht/Boston/London: Kluwer Academic Publishers.

Christie, F. \& Macken-Horarik, M. (2007) Building verticality in subject English. In F. Christie \& J.R. Martin. Language, Knowledge and Pedagogy. Functional Linguistic and Sociological Perspectives, 156-183. .New York: Continuum.

Deverell, G. (1989).The relationship between English proficiency and academic success at the University of the South Pacific. Directions 11 (1): 10-18.

Geraghty, P. (1984). Language Policy in Fiji and Rotuma. Duivosavosa: Fiji's Languages - their use and their future. Fiji Museum Bulletin, 8, 32-84.

Halliday, M.A.K. (1994a). A Language Development Approach to Education, In J.W. Webster, (2008). Language and Education vol.9, Collected works of M.A.K. Halliday (pp. 368-382). Beijing: The Commercial Press.

Halliday, M.A.K. (1994b). An Introduction to Functional Grammar, (2nd ed.). Edward Arnold Publishers.

Jones, J. (2005). Learning to write in the disciplines: the application of Systemic Functional linguistic theory to the teaching and research of student writing. In L. J.Ravelli \& R.A. Ellis. 'Analyzing Academic Writing. Contextualized Frameworks (pp. 254-274). University of Wales, Cardiff: Continuum.

Khan, V., \& Mugler, F. (2001). The Fiji Form 7 Prescription and the Language Needs of First Year Tertiary students. Directions Journal of Educational Studies. University of the South Pacific, 23(2).

Martin, J.R. (2007). Construing knowledge: a functional linguistic perspective. In F.Christie \& J. R. Martin, Language, Knowledge and Pedagogy. Functional Linguistic and Sociological Perspectives (pp. 34-64). New York: Continuum.

Maton, K., (2007). Knowledge - knower structures in intellectual and educational fields. In F. Christie \& J.R. Martin, Language, knowledge and pedagogy. Functional Linguistic and Sociological perspectives (pp.87-108). London, New York: Continuum.

MICUSP (2010), MICHIGAN Corpus of Upper - Level Student Papers, Retrieved from, search-micusp.elicorpora.info Nunan, D. (1994). Research Methods in Language Learning ( $3^{\text {rd }}$ ed.). Cambridge: Cambridge University Press.

O' Halloran,K., (2007). Mathematical and scientific forms of knowledge: a systemic functional multimodal grammatical approach. In F. Chritie, \& J. R. Martin, Language Knowledge and Pedagogy. Functional Linguistic and Sociological Perspectives (pp. 205-238). London, New York: Continuum.

Silva,T. (1997). Differences in ESL and Native-English-Speaker Writing: The Research and Its Implications. In C. Severino, J. Guerra, \& J. Butler, Writing in Multicultural Settings (pp.209-219). New York: The Modern Language Association of America.

Thompson, G. (1996). Introducing Functional Grammar. Edward Arnold Publishers.

Vygotsky, L.S. (1987). Thinking and Speech. The collected Works of L.S. Vygotsky (1): Problems of general psychology. New York: Plenum Press.

Wen, Q. (2001). Applied Linguistics: Research Methods and Thesis Writing. Nanjing University: Foreign Language Teaching and Research Press.

Yang, L. (2006). An analysis of Chinese students' academic writing in a Canadian University. In A. Cumming, Goals for Academic Writing: ESL students and their instructors (pp. 73-89). Amsterdam: Benjamins Publishing Company. 